\title{
MODELING AN INSTITUTIONAL APPROACH TO DEVELOPING TECHNOLOGY ENABLED LEARNING: CLOSING THE GAP BETWEEN RESEARCH AND PRACTICE
}

\author{
Linda Price, Diogo Casanova and Suzan Orwell \\ Kingston University London
}

\begin{abstract}
This paper presents our approach to closing the gap between research and practice when delivering technology enabled learning. We illustrate our model that uses research to underpin how we have shaped a whole institutional roll out of our new VLE, Canvas. The model is built around our Learning Design principles based on current research in the field and key institutional priorities. The model addresses how we lever the implementation of our new VLE as a catalyst for changing the institutional pedagogical paradigm. Our experience shows that by adopting such an approach we are able to positively impact on institutional teaching practices and influence policy to support innovative VLE pedagogy.
\end{abstract}

Keywords: Learning Design, Canvas, Policy, TEL, Staff Development, VLE Templates.

\section{INTRODUCTION}

Although technology uptake for teaching and learning in universities has been considerable, Technology Enabled Learning (TEL) research has had limited impact on implementation, decisions and policy around teaching and learning [1], [2]. While a considerable body of TEL research exists, its influence upon institutional level technological implementations is still limited [3]. More frequently observed are the localised implementations and this usually leads to fragmentation of practices across the institution and a 'disintegrated' student experience [4]. Typically, teachers' Virtual Learning Environment (VLE) designs and online teaching approaches either reflect how they were taught or attempt to replicate face-to-face teaching [5]. Thus VLE learning designs lack research input and institutional contextualization [6]: they are often transmissive in style with limited opportunities for active learning [7]. They are also individualised to teachers' perceptions of how navigation should be designed and how should be presented. This does not always best serve students' needs.

A recent study [8] provided evidence that teachers involved in Blended Learning programmes were not using the VLE to design learning activities, but to distribute resources and manage assignments submissions. The number of wikis, blogs or discussion forums created was sporadic and uneven. Whilst some teachers were extremely engaged with creating new online opportunities and innovative strategies, using images and multimedia to build interactive narratives, others were only using the VLE to make PowerPoint presentations available. This gives students uneven experiences between modules, even in the same course, potentially confusing them and disrupting their learning.

A UCISA (Universities and Colleges Information Systems Association) report [9] confirms this by suggesting that the use of online learning and teaching in different Higher Education institutions in the UK is still largely confined to accessing external resources or digital repositories, making esubmissions, and using plagiarism detection software. Other student-centred strategies such as asynchronous collaborative working tools, peer-assessment and e-portfolios, are far from being the mainstream (less than 25\% of the Higher Education teachers are using one of these strategies in their teaching). VLE providers and institutional polices also do not help to promote better online delivery. Whilst VLE providers develop solutions that encompass $\mathrm{K} 12$, higher and further education needs individual institutions focus on administrative and functional tasks. The two approaches are not mutually inclusive. Godwin-Jones [10] suggests that the design of VLEs has not evolved dramatically since mid-1990. Instructors and students are still using VLE's to upload/download documents, use online gradebooks, track assignments and use fixed-format assessments methods [10]. In some cases, the VLE is even used to provide an online mirror of traditional didactic classroom activities [11], focusing on instructions and content provided by the tutor. Thus little pedagogical advantage is made of the technology and often these 'replication' approaches provide students with an even worse experience [7]. 
In Higher Education, pedagogical activities are still seen as somewhat difficult to implement online and with a lower value to students. Allen and Seaman [12] found that a third of US Higher Education institutions believed that the online learning outcomes have a lower complexity when compared with of traditional face-to-face learning outcomes. This suggests that teachers delivering Blended Learning courses are not reflecting on the different characteristics of online delivery. Rather, they focus on transposing what they teach face-to-face into a Virtual Learning Environment [7] [8]. To make the best use of technology, we need to go beyond opinion and 'gut instinct' and adopt a scholarly and evidence-informed approach to TEL [13]. Furthermore, we need to build institutional models for TEL that involve Policy and Guidance, Staff Development and Support, an Institutional Learning Design approach and consistent and more active Delivery [14].

\section{DIFFICULTIES IN DEVELOPING PEDAGOGICALLY LED APROACHES}

One of the difficulties in advancing a TEL university approach to is to go beyond the noble, although often disconnected, educational technology innovations developed by TEL enthusiasts. Typically, these tend to lead to wide institutional variation in TEL instantiations and indeed how they connected with the underlying institutional infrastructure (see, for example, UCISA, [9]). What has become clear over the past decade, is the need for sustainable approaches to developing TEL that link with underlying institutional infrastructure, whilst also providing students with a stake in their educational opportunities and experiences.

Achieving effective TEL adoption has been more difficult than policy-makers had foreseen. This has been manifested not only at the institutional level, but also the course level, where module design and assessment policies are not congruent with each other or with the course as a whole. More often than not this is a result of ambiguity about the rationale, approach and infrastructure support regarding TEL implementation [15]. Equally there have been diverse perspectives held by stakeholders who have often acted autonomously and not necessarily to the benefit of the overall institutional outcomes [16], [17].

Institutions are also subject to external influences that can either enhance or derail particular TEL initiatives. For example, in the UK many institutions are preparing for the Teaching Excellence Framework (TEF) that will benchmark the quality of an institution's teaching. This is significant for UK institutions as it will further determine their national rankings and possibly revenue, if students are negatively affected by their perceptions of the teaching quality of an institution.

A crucial component in effective institutional implementations of TEL is the teaching staff. They will have diverse beliefs about and approaches to teaching and learning [18]-[20]. They will also exhibit variations in their identity [21], [22]. These all influence how they believe they should teach and how they go about it, particularly in relation to TEL [5].

A further highly influential factor is the underlying context within which Higher Education teachers work [23]. They are influenced not only by the departmental culture and structures but also the institutional one. For example, if an institution has a research-intensive culture, academics are more likely to concentrate on their research as a more definitive means to gain promotion [4]. This inadvertently focuses attention away from teaching [24] and hence engagement with TEL interventions is more difficult.

Kirkwood and Price [4] model the complexity in four influential and interrelated factors influencing the instantiation of effective institutional approaches to TEL:

- the teacher's academic context;

- the student's academic context;

- the departmental context;

- the institutional context.

Figure 1 (adapted from Kirkwood and Price, [4]) illustrates these factors and the relationships between them. Stronger influences and their principal direction, is show by a bold arrow. Weaker influences are illustrated by a lighter, broken line with the predominant direction of flow indicated. 


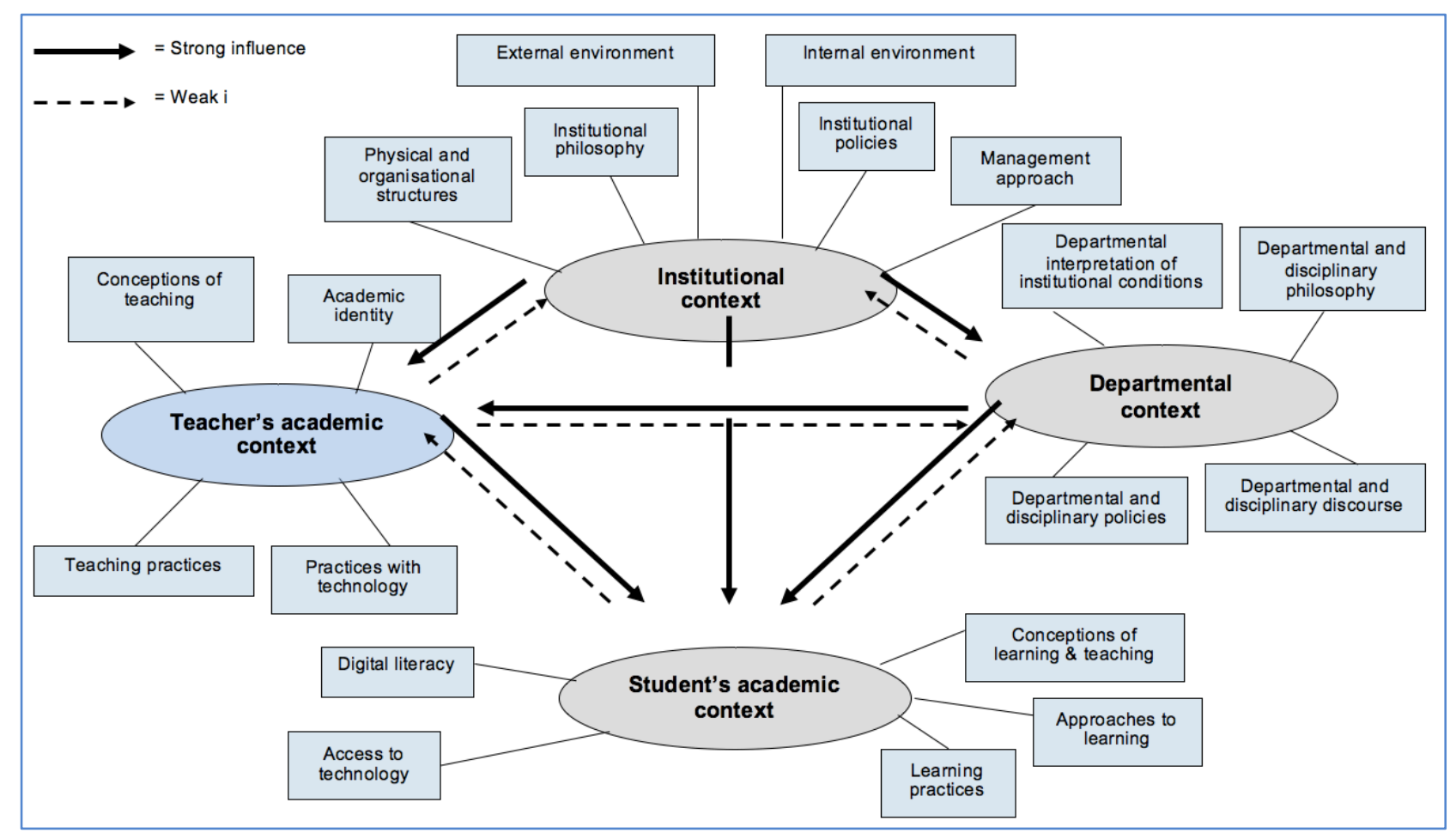

Figure 1: Factors influencing teaching and learning with technology in Higher Education: a framework (adapted from Kirkwood and Price

The diagram illustrates the complexity of these factors and their influences. Many of these are conflicting. Hence a simplistic approach to implementing TEL is likely to be unsuccessful if these factors and their concomitant influences are not addressed in the overall institutional approach.

\subsection{An institutional approach to TEL}

An important step in advancing a coherent and consistent approach to TEL across the institution is to gather evidence about what current experiences and issues might be and what the future institutional needs might be. This will also require an oversight of the current technological infrastructure and its ability to meet current and future needs. Visions of TEL implementations need to advance from historical perspectives on teaching and learning rooted in simple transactions between teacher and students within a closed room. Appropriate technical infrastructure must be installed and maintained within the institution that underpin and support the overall educational agenda.

As such, academic staff will require professional development beyond a features-based approach to understanding the technical capabilities of any TEL implementation: Staff professional development must focus on how to lever the technology for pedagogic purposes.

Additionally, students will need support in adapting to new practices that advance their academic studies through using digital technologies. This will also pose challenges for heads of departments and faculty managers, as they have to rethink resource allocation and monitoring due to the new approaches to developing digital materials for teaching and learning.

Development of digital resources and supporting infrastructure requires specialist input from Learning Technologists, Web Developers, Library Specialists and Information Technology experts. Thus, any advancement in preparing for a coherent and consistent TEL implementation should go beyond a focus on teachers and learners, and should include technical and support staff, administrators and senior managers and policy makers.

Any advancement in TEL also needs to work seamlessly with physical spaces as well as the technology. If we are going to provide students with an integrated and seamless educational experience, we need to consider how both the physical and virtual space can work congruently. This requires teachers and policy makers to consider both of these areas simultaneously. For teachers it may mean changes in design practices, where the design is driven by a strong agenda of what the 
educational purposes of any programme of study are, as opposed to what 'content' may be in any programme of study. Similarly, policy makers will need to consider how changes in Learning Designs, and the balance of interaction between face-to-face and virtual, may impact upon the physical infrastructure. This encompasses decisions such as removing large lecture theatres and replacing them with technology-enhanced collaborative spaces [25], [26], as well as reconsidering offices and residential accommodation. The primary concern in leveraging virtual and physical spaces purposefully needs to be underpinned by the adequacy and appropriateness of those spaces for their intended purposes.

\subsection{Levering the research to advance practice}

Typically TEL in Higher Education has not been pedagogically grounded, frequently existing teaching using technology [27], [28] [29]. There are also concerns as to whether TEL will positively impact on education in the future [30]. Attwell and Hughes [30] found that the biggest barrier is the gap between research and practice. Pedagogical research and TEL implementations have progressed seemingly independently, with limited cross-fertilisation [3].

There is much discussion in Higher Education about improving the quality of student learning. However, it is often the least debated aspect of educational change: typically concepts of how to improve are assumed and uncontested [31]; this is more acute in TEL institutions [4].

Price [32] has shown that a contributing factor is the simplistic manner in which teaching and learning in general are treated. She argues for a more holistic approach that can model all of the inter-related factors and thus identifies the scope of the problem. As Bates [33] argues the problem is not with the technology per se but our hesitation in embracing its complexity. It may be that the complexity of addressing the requirements of diverse stakeholders with different perspectives, varying departmental and institutional contexts, and variations in academic ideology and teaching practice, is rather daunting [23].

Higher education is not the only field dealing facing issues in putting research into practice. Gawande [34], talking about 'The Future of Medicine' in a Reith Lecture, argued for a 'systems approach' to medicine in order to effectively improve its quality and to address its increasing complexity. This involves moving away from a 'one-physician one-diagnosis' model to a collaborative diagnosis where the inter-relationship and inter-dependencies between different branches of medicine could be embraced. Such approaches provide a holistic diagnosis where a number of specialists work together to find the best overall solution for the individual patient.

Higher education faces similar problems: its research too has increased in volume and complexity. Nonetheless, the nature of learning still tends to be taken for granted. Take, for example, the recent fad for massive open online courses (MOOCs): it is an educational approach that perpetuates teachercentred transmissive teaching practices and ignores research findings about good educational practice [35], [36]. But how can we get busy faculty staff and managers to engage with this complexity? Whilst the field of education has a long and well-documented set of methods for examining practice and theorising it, there is not the same reciprocal set of actions for taking theory and for re-injecting into effect individual institutional practice. In this paper, we illustrate how we have approached this problem. We present a TEL Model of how we have engaged with institutional stakeholders, institutional policy and current research in order to close the gap between research and practice.

\section{CONTEXT}

Our TEL Model is located in Kingston University, London (KUL). It is a middle size university in the United Kingdom with approximately 20.000 students and offers mainly Blended Learning programmes, which combine face-to-face teaching with some online delivery and assessment. The university comprises five faculties, each divided into Schools and Departments.

KUL had been using BlackBoard ${ }^{\mathrm{tm}}$ as its VLE since 2002. Although staff were familiar with Blackboard, our evidence showed that they had developed limited active learning and student interaction [8]. Student feedback showed significant difficulties in locating resources, assessment and feedback. They also complained about the lack of consistency in how modules were presented, even within the same course. As both online assessment and learning materials storage were seen as the two main VLE 
features, both in KUL and in the wider UK HE sector [8], [9] it underscored less effective learning designs and lack of transparency.

The transition to another VLE was seen as a window of opportunity for the institution to respond to these problems and to guarantee consistency and coherency across the different modules of a course. It was also seen as an opportunity to build policy and guidelines that were influenced by institutional priorities, university educational policies and current research and best practices in the field. 'Succeed' is our project which is developing and supporting the transition of the VLE from BlackBoard $^{\mathrm{tm}}$ to Canvas ${ }^{\mathrm{t} m}$. It is a vehicle that is enabling us to adopt an institutional approach to improve the quality of student learning by building on TEL research, institutional evaluations and institutional priorities to change practice. We developed the TEL 'Research to Practice' Model in order to understand important factors that influence the adopting of TEL so that we could enable appropriate change in a pragmatic manner.

Like most universities KUL is influenced by internal and external drivers. In the UK, the National Student Survey (NSS) and the impending Teaching Excellence Framework (TEF) are powerful forces within institutions and currently have significant impact upon university agendas and strategies. While institutions have particular missions and agendas, these are significantly influenced by external agendas, particularly in relation to how they respond to the changing national HE environment. Equally, research and evaluations are important considerations too, especially if an institution is to make effective change with TEL. All of these things need to be considered holistically in order to drive institutional change and to make a lasting and sustainable change across the university. Figure 2 illustrates the 'TEL Research to Practice Model' and the factors that need to be considered in order to close the gap between research and practice and lever internal agendas to effectively roll-out the new VLE.

The TEL Model has been implemented through our 'Succeed' project. The project started in September 2016 with four main components: the development of Learning Design principles, the design of module templates in Canvas, the delivery of staff development activities and Canvas module quality evaluation. In the next sections, we will present an overview of each component and some of the strategies. 


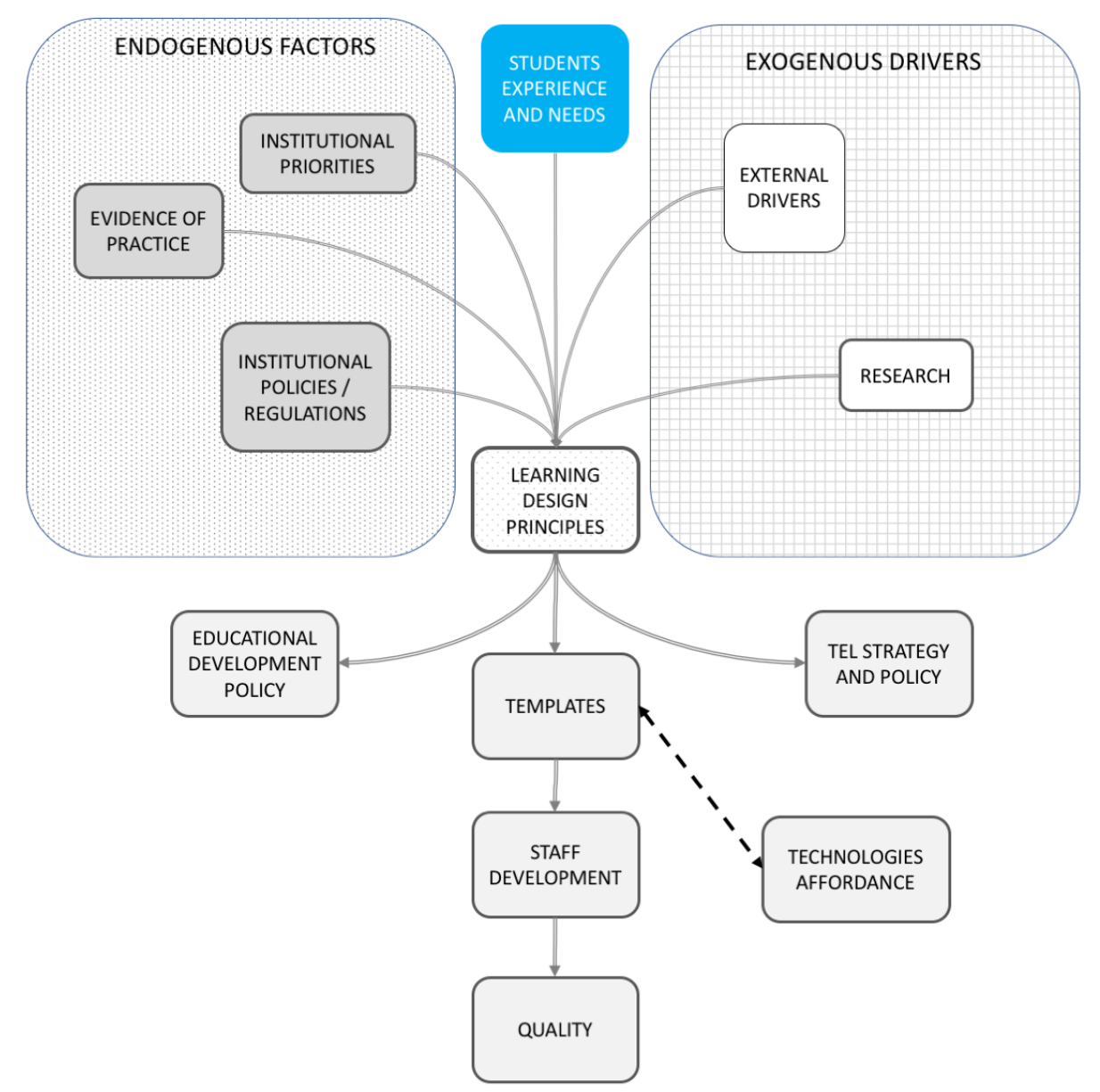

Figure 2, TEL Research to Practice Model

\subsection{From research and policy to Learning Design principles}

Learning design is a term used in Educational Technology to describe how a course or a module has been designed in a Virtual Learning Environment [37], [38]. Learning Design principles provide guidance on how best to design modules and courses in a VLE.

The Twelve Learning Design principles were developed to foster curriculum design for every module in the new VLE. The principles are informed by both (i) endogenous drivers which were institutional priorities, policies and evidence of good practice and (ii) exogenous factors which are related with evidence of research, external drivers and students' satisfaction and needs (see figure 2).

Endogenous drivers refers to aspects related to how the institution operates that are relevant for embedding learning and teaching practices online. These are seen by senior managers and policy makers as key for the university and need to be disseminated throughout the Learning Design approach of the new VLE. Within KUL, the Learning Design principles were informed by policies and institutional priorities such as the Educational Vision and Strategy, the Academic Framework, the Equality, Inclusivity and Accessibility agenda and good practice in learning and teaching initiated by some Faculties in the university. Our Educational Vision and Strategy document encourages practice in KUL to be influenced by three main aspects: (i) Learning, Enquiry and Practice; (ii) Enriching lives; and (iii) Respect for individuals, communities and the environment. Our Academic Framework provides an 'architectural structure' within which experts can construct and tailor their courses according to the needs of their students and their discipline. It scaffolds main pedagogical decisions for curriculum design for those academic staff that are not specialists in education but who may be specialists in their disciplinary fields.

The Inclusive Curriculum Framework provides a set of guidelines for curriculum and assessment design, which are tailored to support all students by conceiving students diversity needs from conception. This framework therefore encourages embracing diversity in curriculum and assessment 
design. Equally, good practice in Assessment Design, Feedback and Quality Assurance which were initiated and followed by some KUL Departments, Schools and Faculties have also contributed to the Learning Design principles.

The exogenous factors are related with evidence of research, external drivers and student satisfaction and needs. With regards to evidence of research we were influenced mainly but not exclusively by the frameworks provided by the Universal Design for Learning (UDL) [39], the Excellence framework [40] and Biggs [41] Constructive Alignment.

Universal Design for Learning [39] is a framework developed to guide educational practice in terms of the manner in which information is provided, expectations regarding students responses or skill demonstration, how knowledge is provided, and how students are engaged. This aim overall is to remove unnecessary barriers to learning. The UDL framework is based on the idea that a learning environment should include the curriculum, instruction and material that are accessible to a wider population of students with different abilities. Expanding accessibility to a wider population of students with different abilities requires proactive instructional design instructional strategies and technology to support multiple means of knowledge, representation, engagement and expression of understanding [42], [43].

E-xcellence is the name of a project started in 2005, funded by the European Union, which aimed to define a set of quality standards in e-Learning. The project included some of the most relevant European institutions in this area, such as the Open University in the UK, the Open Universiteit Nederland or the Universitat Oberta de Catalunya. The model proposes the existence of six dimensions for evaluating e-Learning provision: (i) strategic management, (ii) curriculum design, (iii) course design, (iv) course delivery, (v) staff support and (vi) student support. The model presents a useful set of benchmarks for each dimension aiming to facilitate the understanding of what is intended as quality for each of the mentioned aspects [40].

An important component of this is making sure that what you are teaching and assessing is actually helping students to succeed in their studies. Constructive alignment is an important and useful underpinning model in Higher Education that points to the need to align learning outcomes, assessment and learning activities when designing curriculum. Biggs [41] argues that by designing the curriculum based on the learning outcomes we foster transparency to students about what outcomes are expected from their learning, thus providing more student-centered learning.

The TEF and the National Student Survey (NSS) are both key external drivers for the UK Higher Education sector. Whilst the TEF aims to provide a series of metrics to assess the quality of teaching for each institution the NSS provides a ranking of students' satisfaction in teaching, assessment and feedback, learning opportunities, academic support and organisational management. Both these mechanisms are used to generate league tables which rank Higher Education institutions and may impact on the institution reputation and future recruitment. It is therefore natural that institutions support initiatives that improve student satisfaction with course provision as they may impact in their classification in the NSS and in the TEF.

The Twelve Learning Design principles were presented to colleagues in KUL as part of the "Designing Learning in a Virtual Learning Environment: Leveraging Technology to Support Student Learning" document and was approved internally by the University's Educational Committee. Each principle was presented with a series of guidelines to support academic staff to understand each principle and to ensure that staff can identify their relevance to their practice. An example of one of the principles is the first Learning Design Principle: 'Design that is universal'. This principle suggests that when designing technology enhanced learning activities, all learners must have comparable learning opportunities whatever their cultural, economical or physical limitations. This implies that, by default, activities and resources are available in the same way to all students, and when this is not possible, alternative paths are provided so that all learners have similar experiences.

\subsection{From Learning Design principles to VLE module templates}

The institutional support for providing a more consistent Learning Design experience for staff and students led to the next phase of the project; the design of VLE module templates. The templates underpinned a new pedagogical paradigm for the online learning delivery at the institution. The templates were designed using HTML and CSS (Cascading Stylesheets). The templates were designed using Learning Design principles, best practice guidelines in using the VLE and accessibility 
guidelines. The templates are responsive which means that reading and navigation is possible with a minimum of resizing, panning, and scrolling-across a wide range of devices (from desktop computer monitors to mobile phones). The aim is to create a consistent identity, structure and navigation using the University brand and colour schemes. In essence our templates encompass:

- $\quad$ The Home Page Template: this template has (i) module name, (ii) links to the syllabus page, the assessment and feedback page and the reading list; (iii) an area with the topics structure and the module team contacts and pictures. The organisation of all modules within a topic structure rather than a linear and time oriented structure suggested a significant shift of how online learning was being used at the institution;

- The Syllabus Page Template: this template provides the relevant information students need to have before sart fo the module (aims, learning outcomes, the module matrix and the calendar with events and assignments);

- The Assessment and Feedback Page Template: this template has all the assessments, as well as their brief, how students will be assessed and when feedback and grades would be released;

- The Topic Page Template: this template has an introduction to the topic and the list of units for the topic.

- The Unit Page Template: this template has all the activities that are associated within a unit.

\subsection{From Learning Design principles to staff development activities}

Staff development activities were divided into three levels, a Course level, a Module level and a 'Build Your Module' level. In the Course level, Course Directors were invited to attend a short presentation on the benefits of the transition to a new VLE for staff and students using internal and external evidence. They also met with their course team so they could consolidate a consistent approach across their course.

The second level is the Module team. In this level, the Module leader and the teaching team for a particular module were invited to participate in workshop to discuss the transition process of their module into the new VLE using the module templates.

The third level is the 'Build Your Module' workshop, in this workshop; the staff were encouraged to develop their module using a set of instructions and with the help of a team of TEL professionals. This workshop is followed by one-to-one sessions to ensure that staff are confident in using the VLE.

\subsection{From learning design principles to VLE module quality evaluation}

Fresen et al. [44] suggested a collection of electronic course templates for use in Higher Education and argued that pedagogical proposals such as templates are difficult to evaluate in this context, where ideas are constantly refined. However, we are following an agile approach that consists of three elements, firstly, strong communication strategy to enable us to work with staff directly, frequently and easily. Secondly, a shared checklist between Module leaders and TEL professionals, the checklist has a set of standard content for each template to ensure consistency. Finally, we are facilitating a peer review procedure among staff as part of a quality assurance process to share good practice and to maintain the desired level of consistent VLE. So while we understand the limitations of templates, for many of our staff they are a more pragmatic way to get a large body of staff to develop courses that take advantage of the research, advance university agendas and advance the quality of student learning.

\section{Conclusion}

In this paper we have presented a model that articulates our approach to closing the gap between research and practice when delivering Technology Enabled Learning. Our model enabled us to deal with the complex factors that influence a teaching and learning eco system in a university. It highlighted the need to address the university's priority of improving student learning satisfaction through the provision of a consistent and coherent learning environment. The model underpins the development of our Learning Design principles that guided the development of our VLE module templates. This enabled us to provide practitioners with a tangible approach to embodying sound research evidence, students' experiences and institutional priorities in a pragmatic manner. The 
strength of this approach is in the ability to lever the instantiation of the new VLE as a change-agent for pedagogical improvement. Our experience shows that by adopting such an approach we are able to have a positive impact on institutional teaching practices and influence policy to support innovative VLE pedagogy. While our evaluation is at an early stage, our findings have shown that we have already gained improvements in the structuring and delivery of teaching, staff engagement in pedagogical change, quality assurance processes, institutional and management support, assessment practices, increased transparency and better sharing of good practice.

\section{REFERENCES}

[1] T. A. Angelo, "A Teacher's Dozen: fourteen general research-based principles for improving higher learning in our classrooms," American Association for Higher Learning Bulletin, vol. 45, no. 6, pp. 3-13, 1993.

[2] R. Breen, R. Lindsay, A. Jenkins, and P. Smith, "The Role of Information and Communication Technologies in a University Learning Environment," Stud. High. Educ., vol. 26, no. 1, pp. 95114, Mar. 2001.

[3] L. Price, A. T. Kirkwood, and J. T. E. Richardson, "Mind the gap: the chasm between research and practice in teaching and learning with technology.," in Researching Higher Education: International Perspectives on Theory, Policy and Practice, J. Case and J. Huisman, Eds. 2015, pp. 227-245.

[4] A. Kirkwood and L. Price, Technology Enabled Learning: Handbook. BC Canada: Commonwealth of Learning, 2016.

[5] C. Englund, A. D. Olofsson, and L. Price, "Teaching with technology in higher education: understanding conceptual change and development in practice," High. Educ. Res. Dev., pp. 115, Apr. 2016.

[6] L. Price and A. Kirkwood, "Informed design of educational technology for teaching and learning? Towards an evidence-informed model of good practice," Technol. Pedagog. Educ., vol. 23, no. 3, pp. 325-347, Jul. 2014.

[7] L. Price and A. Kirkwood, "Using technology for teaching and learning in higher education: a critical review of the role of evidence in informing practice," High. Educ. Res. Dev., vol. 33, no. 3, pp. 549-564, 2014.

[8] H. van der Sluis and S. May, "Tag to track? Analytics to measure the impact of educational policies," Brookes e-Journal Learn. Teach., vol. 7, no. 2, 2015.

[9] R. Walker, J. Voce, J. Nicholls, E. Swift, J. Ahmed, S. Horrigan, and P. Vincent, "2014 Survey of Technology Enhanced Learning for higher education in the UK," Oxford, 2014.

[10] R. Godwin-Jones, "Challenging Hegemonies in Online Learning.," Lang. Learn. Technol., vol. 16, no. 2, pp. 4-13, 2012.

[11] M. Sigala, "The evolution of internet pedagogy: Benefits for tourism and hospitality education," J. Hosp. Leis. Sport Tour. Educ., vol. 1, no. 2, pp. 29-45, 2002.

[12] I. E. Allen and J. Seaman, Changing Course: Ten Years of Tracking Online Education in the United States. ERIC, 2013.

[13] A. Kirkwood and L. Price, "Missing: evidence of a scholarly approach to teaching and learning with technology in higher education," Teach. High. Educ., vol. 18, no. 3, pp. 327-337, Apr. 2013.

[14] D. Casanova, A. Moreira, and N. Costa, "A four levels framework to understand quality practices in active e-Learning," in ECER Conference, 2014.

[15] A. Kirkwood and L. Price, "Improving quality and validity in research and evaluation studies of learning technologies," in Proceedings of the 6th International Conference on Education and New Learning Technologies, 2014.

[16] S. Marshall, "Change, technology and higher education: are universities capable of organisational change?," Res. Learn. Technol., vol. 18, no. 3, pp. 179-192, 2010.

[17] S. Price and M. Oliver, "A Framework for Conceptualising the Impact of Technology on Teaching and Learning," Educ. Technol. Soc., vol. 10, pp. 16-27, 2007.

[18] M. Prosser, P. Ramsden, K. Trigwell, and E. Martin, "Dissonance in Experience of Teaching and its Relation to the Quality of Student Learning," Stud. High. Educ., vol. 28, no. 1, pp. 3748, 2003.

[19] K. Trigwell, M. Prosser, and F. Waterhouse, "Relations between teachers' approaches to teaching and students' approaches to learning," High. Educ., vol. 37, pp. 57-70, 1999.

[20] K. Trigwell and M. Prosser, "Development and use of the approaches to teaching inventory," Educ. Psychol. Rev., vol. 16, no. 4, pp. 409-424, 2004. 
[21] N. McLean and L. Price, "The Mechanics of Identity Formation: A Discursive Psychological Perspective on Academic Identity," in Identity Work in the Contemporary University: Exploring an Uneasy Profession, vol. 1, J. Smith, J. Rattray, T. Peseta, and D. Loads, Eds. Rotterdam, The Netherlands: SensePublishers, 2016, pp. 45-57.

[22] N. McLean, "Researching academic identity: using discursive psychology as an approach," Int. J. Acad. Dev., vol. 17, no. 2, pp. 97-108, Jun. 2012.

[23] J. Fanghanel, "Local responses to institutional policy: a discursive approach to positioning," Stud. High. Educ., vol. 32, no. 2, pp. 187-205, 2007.

[24] E. L. Boyer, Scholarship reconsidered: Priorities of the professoriate. Princeton, NJ: Princeton University Press, 1990.

[25] R. J. Beichner, "History and evolution of active learning spaces," New Dir. Teach. Learn., vol. 2014, no. 137, pp. 9-16, 2014.

[26] D. Casanova, "Participatory Approaches for Designing Technology-Enhanced Learning Spaces: The Experience of Redesigning the 'Cube' and the 'Poppy,'” in EDULEARN16 Proceedings, 2016, pp. 6747-6756.

[27] F. Blin and M. Munro, "Why hasn't technology disrupted academics' teaching practices: Understanding resistance to change through the lens of activity theory," Comput. Educ., vol. 50, no. 2, pp. 475-490, 2008.

[28] G. Roberts, "Teaching using the web: Conceptions and approaches from a phenomenographic perspective," Instr. Sci., vol. 31, no. 1, pp. 127-150, 2003.

[29] A. Kirkwood and L. Price, "Technology-enhanced learning and teaching in higher education: what is 'enhanced'and how do we know? A critical literature review," Learn. Media Technol., vol. 39, no. 1, pp. 6-36, 2014.

[30] G. Attwell and J. Hughes, "Pedagogical approaches for using technology literature review," (Pontydysgu) for Lifelong Learning, UK, Sep. 2010.

[31] F. Coffield, "Just suppose teaching and learning became the first priority," Learning and Skills Network, Holborn Centre, London, ISBN 978-1-84572-708-6, 2008.

[32] L. Price, "Modelling factors for predicting student learning outcomes in higher education," in Learning patterns in higher education in the 21st century: dimensions and research perspectives, D. Gijbels, J. Richardson, and V. Donche, Eds. Routledge, 2014, pp. 56-77.

[33] T. Bates, "The future of learning," in First Presented at the Minister's Forum on Adult Learning, Edumonton/Alberta, November, 1995.

[34] A. Gawande, Being mortal: medicine and what matters in the end. Macmillan, 2014.

[35] J. Daniel, "Making sense of MOOCs: Musings in a maze of myth, paradox and possibility," $J$. Interact. Media Educ., vol. 2012, no. 3, 2012.

[36] V. L. B. Dolan, "Massive online obsessive compulsion: What are they saying out there about the latest phenomenon in higher education?," Int. Rev. Res. Open Distrib. Learn., vol. 15, no. 2, 2014.

[37] D. Laurillard, Teaching as a design science: Building pedagogical patterns for learning and technology. Routledge, 2013.

[38] G. Conole, M. Dyke, M. Oliver, and J. Seale, "Mapping pedagogy and tools for effective learning design," Comput. Educ., vol. 43, no. 1, pp. 17-33, 2004.

[39] J. D. Basham, S. J. Smith, and A. L. Satter, "Universal Design for Learning: Scanning for Alignment in K-12 Blended and Fully Online Learning Materials," J. Spec. Educ. Technol., vol. 31, no. 3, pp. 147-155, 2016.

[40] K. Williams, K. Kear, and J. Rosewell, "Quality Assessment for e-Learning: a Benchmark Approach," Europeean Association of Distance Teaching Universities (EADTU), Heerlen, 2012.

[41] J. Biggs, "Aligning teaching for constructing learning," High. Educ. Acad., pp. 1-4, 2003.

[42] J. D. Basham, M. Israel, J. Graden, R. Poth, and M. Winston, "A comprehensive approach to RTI: Embedding universal design for learning and technology," Learn. Disabil. Q., vol. 33, no. 4, pp. 243-255, 2010.

[43] A. Meyer and D. H. Rose, "Universal Design for Individual Differences.," Educ. Leadersh., vol. 58 , no. 3, pp. 39-43, 2000.

[44] J. W. Fresen, R. K. Hill, and F. Geng, "A collection of suggested electronic course templates for use in higher education," Res. Learn. Technol., vol. 22, 2014. 